\title{
GÊNEROS DE HYDRADEPHAGA (COLEOPTERA: DYTISCIDAE, GYRINIDAE, HALIPLIDAE, NOTERIDAE) CITADOS PARA O BRASIL, COM CHAVES PARA IDENTIFICAÇÃOO.
}

\author{
Cesar João Benetti ${ }^{1}$ \\ Juan Antonio Régil Cueto ${ }^{2}$ \\ Gelson Luiz Fiorentin ${ }^{3}$ \\ Biota Neotropica v3 (n1) -http://www.biotaneotropica.org.br/v3n1/pt/abstract?identification-key+BN00803012003 \\ Recebido em: 14/02/2003 \\ Publicado em: 26/03/2003 \\ 1. Departamento de Ecología y Biología Animal, Facultad de Ciencias, Universidad de Vigo. 36200 - Vigo, Espanha. \\ e-mail: cjbenetti@uvigo.es \\ 2. Departamento de Biología Animal, Facultad de Biología, Universidad de León. 24071 - León, Espanha \\ 3. Laboratório de Entomologia, Centro de Ciências da Saúde, UNISINOS. CP 275 - 93001-970 São Leopoldo, RS
}

\begin{abstract}
The Brazilian fauna of adephagus beetles (Hydradephaga) comprised by the families Dytiscidae, Gyrinidae, Haliplidae and Noteridae is represented by 47 genera and 496 species. We present a list of genera and respective number of species occurring in the Brazilian fauna. Idenfication keys are also provided for the genera of the families Dytiscidae, Gyrinidae and Noteridae. (Haliplidae is represented only by Haliplus).
\end{abstract}

Key-words: Keys, Genera, Hydradephaga, Brasil

\section{Resumo}

A fauna brasileira de coleópteros adéfagos aquáticos (Hydradephaga) formada pelas famílias Dytiscidae, Gyrinidae, Haliplidae e Noteridae está representada por 48 gêneros e 497 espécies. Neste trabalho é apresentada uma listagem de gêneros e respectivo número de espécies citadas para a fauna brasileira. Também são fornecidas chaves para identificação dos gêneros das familias Dytiscidae, Gyrinidae e Noteridae. (Haliplidae está representada somente por Haliplus).

Palavras-chave: Chaves, Gêneros, Hydradephaga, Brasil

http://www.biotaneotropica.org.br 


\section{Introdução}

Os coleópteros da subordem Adephaga de hábitos majoritariamente aquáticos são correntemente denominados Hydradephaga. Para o Brasil esta fauna está constituída por quatro famílias, que segundo Lawrence \& Newton (1995), integram duas superfamílias: Dytiscoidea, formada por Dytiscidae, Haliplidae e Noteridae e Gyrinoidea, formada por Gyrinidae.

O estudo destes coleópteros no Brasil é, até o momento, muito precário na maioria dos grupos. Somente em alguns gêneros há revisões, porém o estudo das espécies de muitas regiões segue sendo inexistente ou muito pontual. Argentina é, provavelmente, o país sul-americano em que há mais estudos nesta fauna, ainda que sejam precários em muitos grupos. O conhecimento das espécies que ocorrem no Brasil, é na sua maioria por descrições ou citações de espécies, feitas na sua quase totalidade até a metade do século XX, a partir de coletas pontuais.

De forma especial há que destacar alguns autores, como Guignot, Zimmermann e sobretudo Ochs que publicou um grande número de trabalhos sobre espécies de Gyrinidae com fauna do Brasil, inclusive de regiões pouco estudadas como Amazônia.

Em anos mais recentes autores como Spangler, Young e Biström, ou os argentinos Bachmann, Tremouilles e Grosso estudaram alguns grupos da fauna neotropical, e publicaram revisões de gêneros e outros estudos taxonômicos.

No Brasil são poucos os trabalhos recentes, destacando-se os estudos de estádios larvais (FerreiraJr.,1993; 1995 e 2000) ou estudos faunístico-ecológicos (Ferreira-Jr. et al.,1998; Benetti et al.,1998).

Desta forma o presente trabalho pretende dar uma contribuição ao conhecimento desta fauna, aportando dados revisados e atualizados sobre os gêneros conhecidos e citados para o país, o número de espécies de cada um e uma chave para identificação destes gêneros.

\section{Material e Métodos}

A listagem de gêneros e espécies foi obtida a partir de uma completa análise de conteúdos realizada através de revisão bibliográfica, considerando todos os trabalhos publicados com descrições de taxons ou citações para o território nacional e catálogos de espécies.

As chaves foram elaboradas a partir de observações feitas com exemplares capturados em Gramado, Rio Grande do Sul, para a tese doutoral do autor, exemplares capturados na Amazônia Central e material depositado na Coleção de
Invertebrados do Inpa e na Coleção Científica do Laboratório de Entomologia da Unisinos, RS. Os caracteres utilizados na construção da chave são próprios ou modificados dos seguintes autores: Régimbart (1902), Ochs (1935), Pederzani (1995), Trémouilles et al. (1995) e Miller (2000, 2001 e 2002).

\section{Resultados e Discussão}

A fauna de Hydradephaga do Brasil está representada, até o momento, por 497 espécies distribuídas em 48 gêneros de quatro famílias: Dytiscidae, Gyrinidae, Haliplidae e Noteridae.

Na lista oficial de gêneros não são consideradas as citações para Brasil do gênero Leuronectes Sharp, 1882 (Dytiscidae), pois foi comprovado que a espécie Leuronectes curtula Régimbart, 1899 citada por Blackwelder (1944) para Brasil, se refere a uma interpretação errônea do "locus tipo" da espécie "San Pablo", Argentina interpretado como sendo "São Paulo", Brasil. O exame correto esclarece o erro, já que na etiqueta consta "San Pablo Tucumán", portanto, Argentina. Trémouilles (2000) cita esta espécie para o Brasil, por transcrição de Blackwelder (1944), por isso esta citação também é considerada inválida.

Também não é considera a citação de Andogyrus ellipticus (Brullé, 1838) (Gyrinidae) para o Brasil, feita por Blackwelder (1944), mencionado como localidade tipo. O exame correto e a análise do publicado por Régimbart (1903) e Ochs (1948), esclarece que o "locus tipo" é Chile, sendo a citação para Brasil considerada como não válida; por isso não se inclui o gênero Andogyrus Ochs, 1924 na listagem da fauna brasileira.

O número total de espécies destas famílias para a fauna brasileira não é exato, já que há duvidas com relação a validade de algumas citações de espécies em diferentes gêneros. Como o estudo desta fauna no Brasil está todavia muito fragmentado e incompleto seria necessária uma revisão de cada um dos gêneros para que se aclarem muitas dúvidas. Seguramente o estudo da fauna da maioria das regiões do Brasil, tais como Amazônia, fará com que a lista de espécies aumente de forma considerável. 
Gêneros de Hydradephaga (Coleoptera) citados para o Brasil

Relação das famílias, subfamílias, tribos, gêneros e subgêneros de Hydradephaga e o número de espécies presentes no território nacional.

Haliplidae Kirby, 1837

Haliplus Latreille, 1802 (Figura 01) H. (Liaphlus) 6 espécies

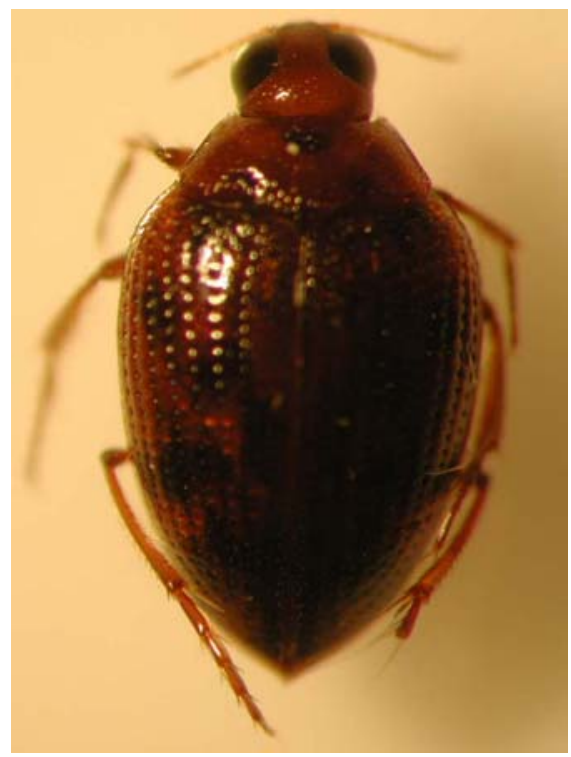

Figura 01 - Haliplus sp. Foto de Benetti, C. J., a partir de exemplares coletados em Gramado, RS.

Gyrinidae Thomson, 1860

Enhydrinae Régimbart, 1882

Enhydrus Laporte, 1834

$$
2 \text { espécies }
$$

Gyrininae Régimbart, 1882

Gyrinini Régimbart, 1882

Gyrinus Müller, 1764 (Figura 02)

G. (Neogyrinus) 10 espécies

G. (Oreogyrinus) 1 espécie

Orectochilinae Régimbart, 1882

Gyretes Brullé, 1834 (Figura 03)

120 espécies

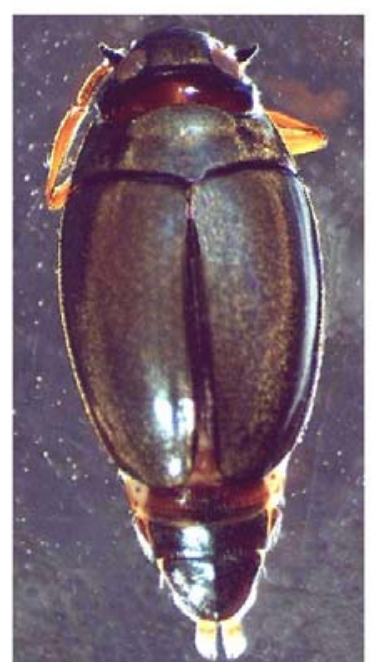

Figura 02 - Vista dorsal de Gyrinus (Neogyrinus) violaceus Régimbart, 1882. Foto de Benetti, C. J., a partir de exemplares coletados no município de Gramado, RS

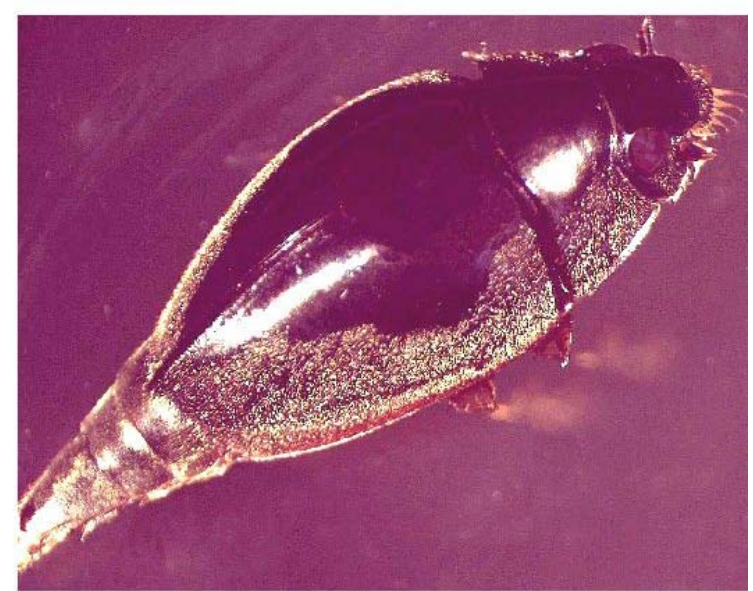

Figura 03 -. Vista dorso-lateral de Gyretes dorsalis Brullé, 1838. Foto de Benetti, C. J., a partir de exemplares coletados no município de Gramado, $R S$

Noteridae Thomson, 1860

Noterinae Thomson, 1860

Hydrocanthini Sharp, 1882

Canthydrus Sharp, 1882

C. (Liocanthydrus) 3 espécies

Hydrocanthus Say, 1823 (Figura 04)

H. (Guignocanthus): 3 espécies

H. (Hydrocanthus) 4 espécies

Suphisellus Crotch, 1873 (Figura 05)

36 especies

Noterini Thomson, 1860

Siolius Balfour-Brown, 1969

2 espécies 


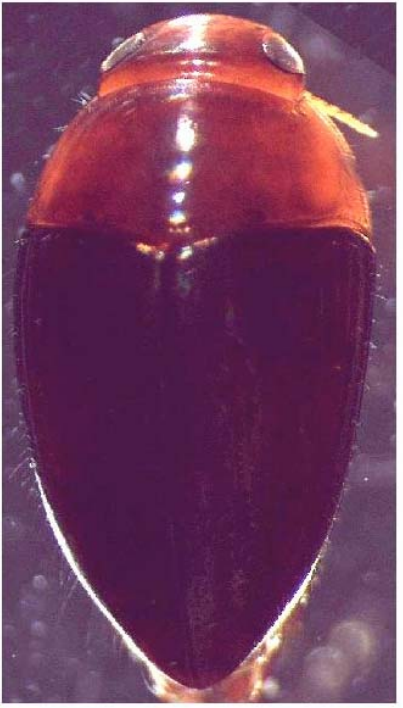

Figura 04 - Vista dorsal de Hydrocanthus (Hydrocanthus) paraguayensis Zimmermann, 1928. Foto de Benetti, C. J., a partir de exemplares coletados no município de Gramado, RS.

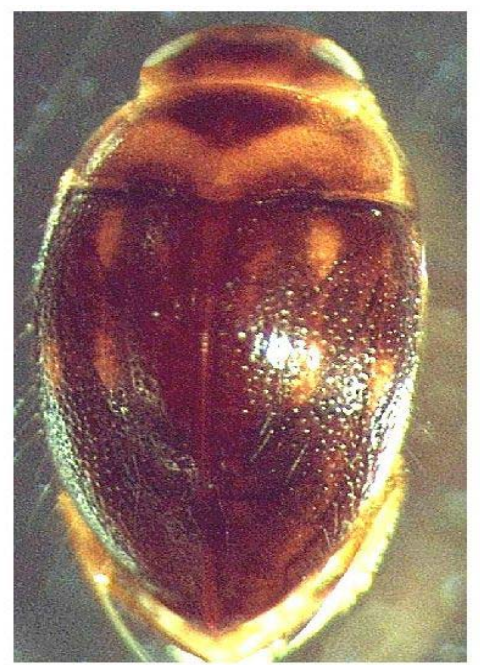

Figura 05 - Vista dorsal de Suphisellus subsignatus (Sharp, 1882). Foto de Benetti, C. J., a partir de exemplares coletados no município de Gramado, RS.

Noterini Thomson, 1860

Siolius Balfour-Brown, 1969

$$
2 \text { espécies }
$$

Noteridae Thomson, 1860

Mesonoterus Sharp, 1882 ((Figura 06)

3 espécies

Notomicrus Sharp, 1882

$$
4 \text { espécies }
$$

Pronoterus Sharp, 1882 (Figura 07)

1 espécie

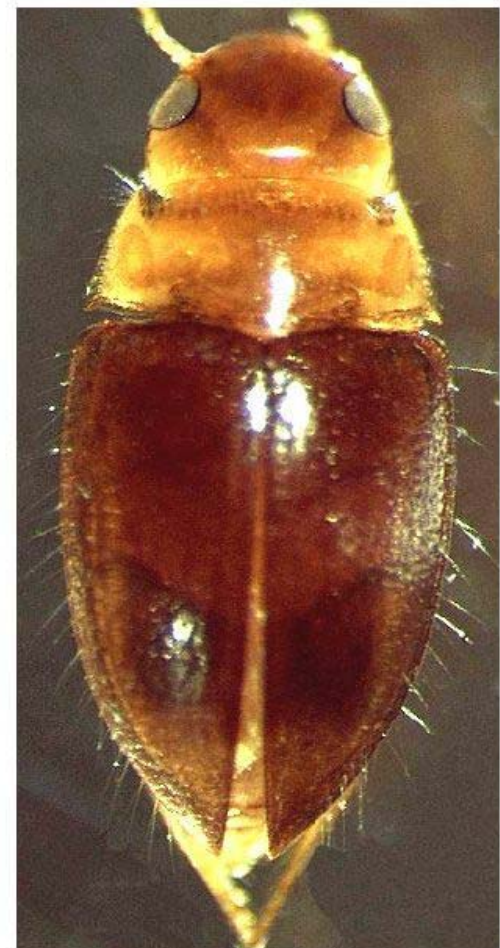

Figura 06 - Vista dorsal de Mesonoterus laevicollis Sharp, 1882. Foto de Benetti, C. J., a partir de exemplares coletados no município de Gramado, RS.

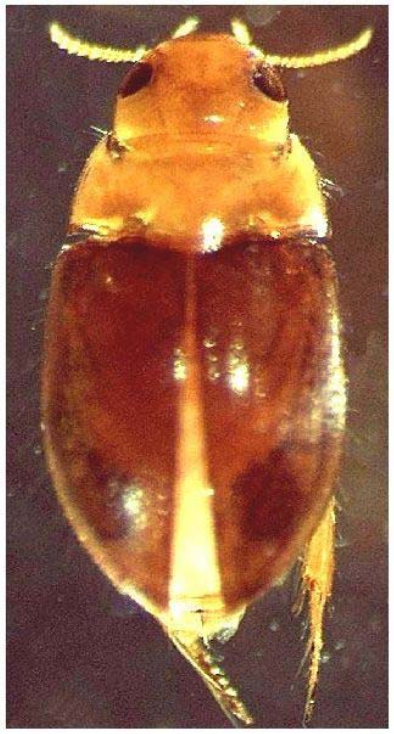

Figura 07 - Vista dorsal de Pronoterus punctipennis Sharp, 1882. Foto de Benetti, C. J., a partir de exemplares coletados no município de Gramado, RS. 
Suphisini Sharp, 1882

Suphis Aubé, 1836

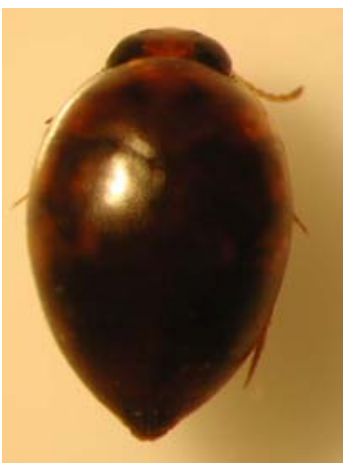

Figura 08 - Vista dorsal de Suphis sp. Foto de Benetti, C. J., a partir de exemplares coletados no município de Camaquã, RS.

\section{9 espécies}

Dytiscidae Leach, 1815

Hydroporinae Aubé, 1836

Bidessini Sharp, 1882

Anodocheilus Babington, 1841(Figura 09)

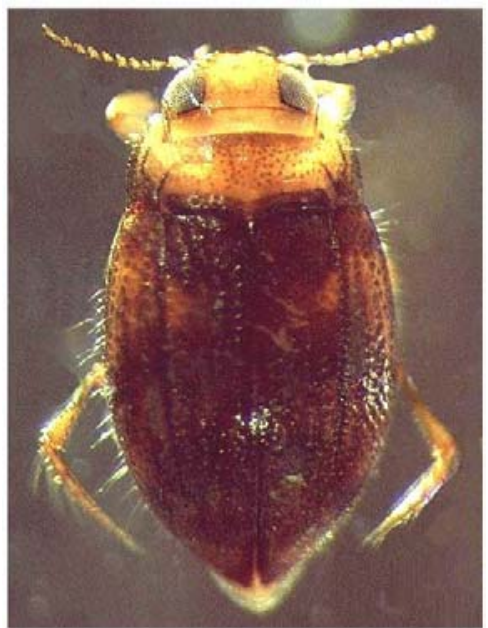

Figura 09 - Vista dorsal de Anodocheilus maculatus Babington, 1841. Foto de Benetti, C. J., a partir de exemplares coletados no município de Gramado, RS.

10 espécies

Bidessodes Régimbart, 1900(Figura 10)

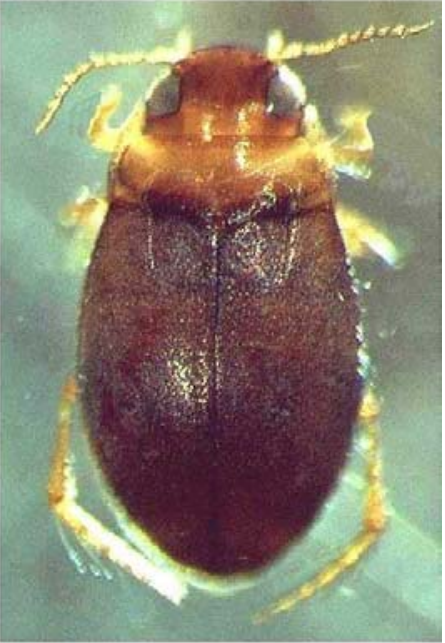

Figura 10 - Vista dorsal de Bidessonotus truncatus J. BalfourBrowne, 1947. Foto de Benetti, C. J., a partir de exemplares coletados no município de Gramado, RS.

$$
\begin{aligned}
& \text { B. (Bidessodes) } 8 \text { espécies } \\
& \text { B. (Hughbosdineus) } 2 \text { espécies } \\
& \text { B. (Youngulus) } 1 \text { espécie }
\end{aligned}
$$

Bidessonotus Régimbart, 1895

$$
7 \text { espécies }
$$

Brachyvatus Zimmermann, 1919

3 espécies

Gramadessus Benetti \& Régil (no prelo) 1 espécie

Hemibidessus Zimmermann, 1921(Figura 11)

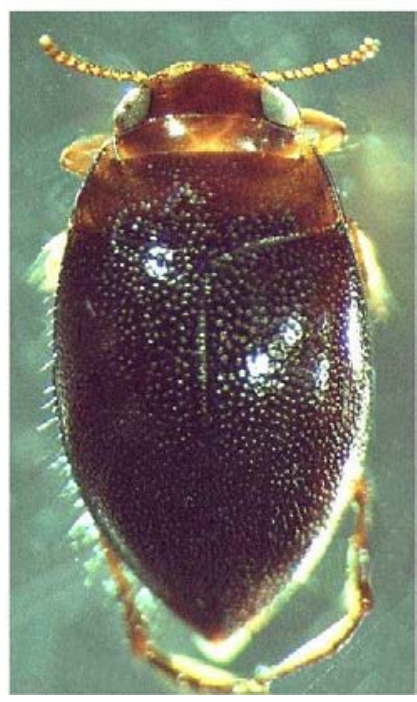

Figura 11 - Vista dorsal de Hemibidessus plaumanni Gschwendtner, 1935. Foto de Benetti, C. J., a partir de exemplares coletados no município de Gramado, RS.

4 espécies 
Hypodessus Guignot, 1939

$$
2 \text { espécies }
$$

Liodessus Guignot, 1939 (Figura 12)

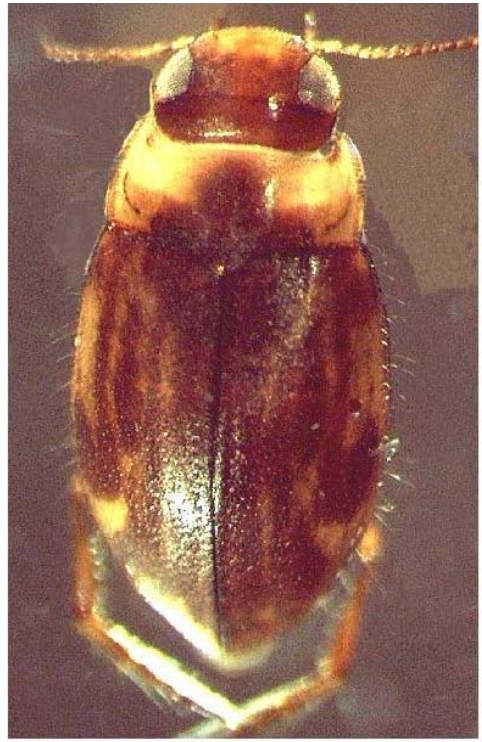

Figura 12 - Vista dorsal de Liodessus affinis (Say, 1823). Foto de Benetti, C. J., a partir de exemplares coletados no município de Gramado, $R S$

\section{9 espécies}

Microdessus Young, 1967

1 espécie

Neobidessus Young, 1967 (Figura 13)

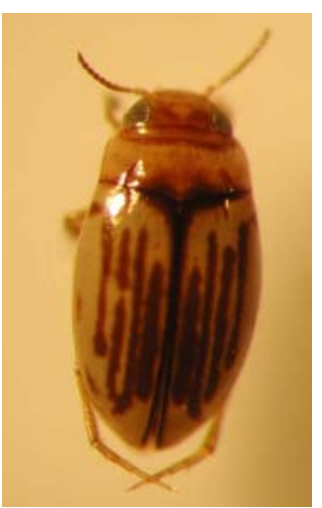

Figura 13 - Vista dorsal de Neobidessus spangleri Young, 1977. a partir de exemplares coletados no municípios de Presidente Figueiredo, AM

13 espécies

Uvarus Guignot, 1939

$$
1 \text { espécie }
$$

Hydroporini Aubé, 1836
(Figura 14)

Laccornellus Roughley \& Wolfe, 1987

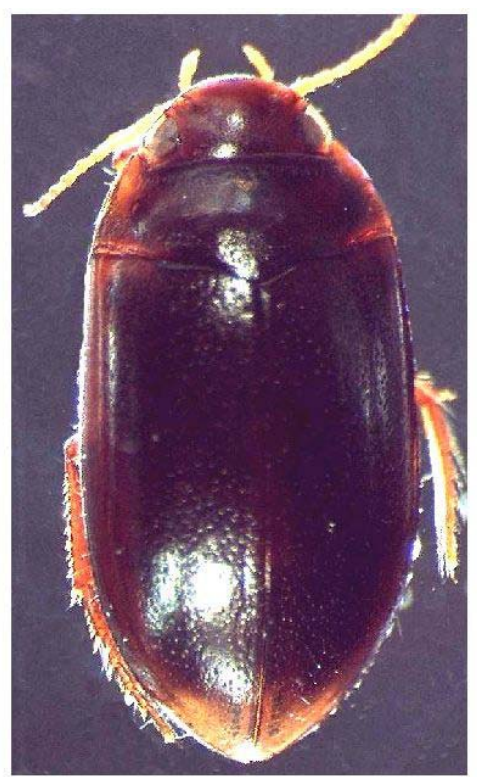

Figura 14 - Vista dorsal de Laccornellus lugubris (Aubé, 1838). Foto de Benetti, C. J., a partir de exemplares coletados no município de Gramado, RS.

$$
1 \text { espécie }
$$

Hydrovatini Sharp, 1882

Hydrovatus Motschulsky, 1853 (Figura

15)

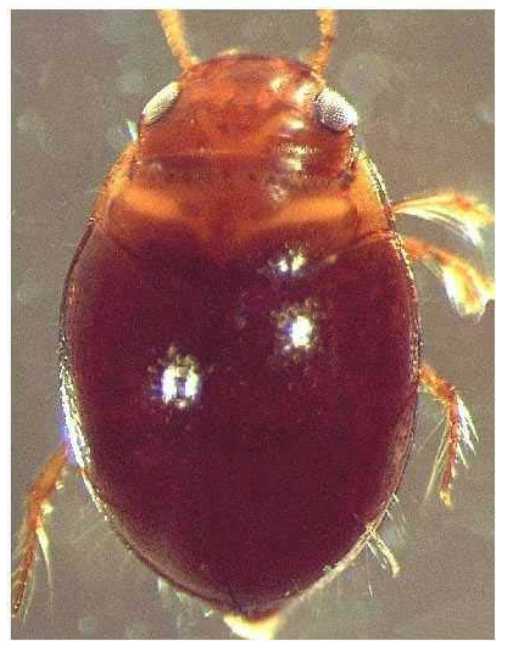

Figura 15 - Vista dorsal de Hydrovatus caraibus Sharp, 1882. Foto de Benetti, C. J., a partir de exemplares coletados no município de Gramado, $R S$.

\section{2 espécies}

Queda Sharp, 1882

3 espécies

Hyphydrini Sharp, 1882

http://www.biotaneotropica.org.br 
Desmopachria Babington, 1841(Figura 16)

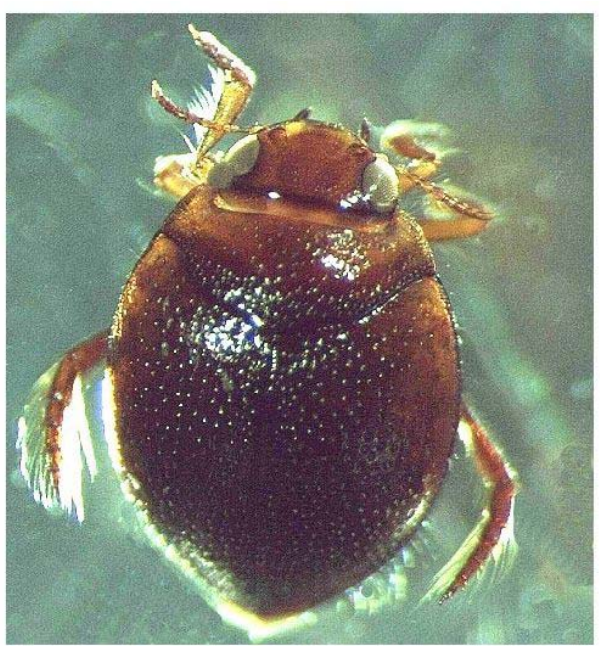

Figura 16 - Vista dorsal de Desmopachria (Pachiridis) aureus Young, 1980. Foto de Benetti, C. J., a partir de exemplares coletados no município de Gramado, RS.

D. (Desmopachria) 17 espécies

D. (Hintonella) 3 espécies

D. (Nectoserrula) 1 espécie

$$
\begin{aligned}
& \text { D. (Pachiridis) } 3 \text { espécies } \\
& \text { D. (Pachriodesma) } 2 \text { espécies } \\
& \text { D. (Pachriostrix) } 6 \text { espécies } \\
& \text { D. (Portmania) } 5 \text { espécies }
\end{aligned}
$$

Pachydrus Sharp, 1882

$$
3 \text { espécies }
$$

Methlini Branden, 1884

Celina Aubé, 1837 (Figura 17)

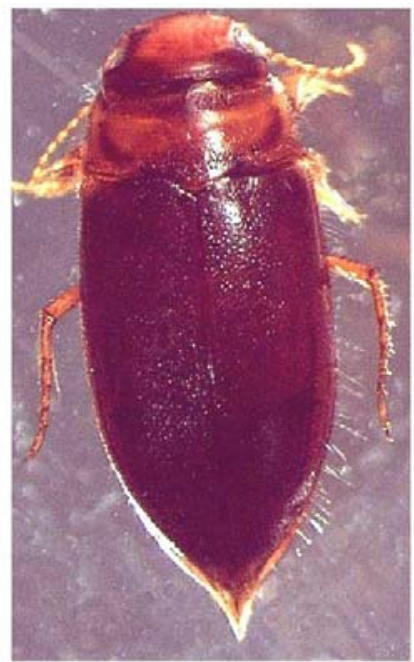

Figura 17 - Vista dorsal de Celina aculeata Aubé, 1838. Foto de Benetti, C. J., a partir de exemplares coletados no município de Gramado, RS.

\section{9 espécies}

Vatellini Sharp, 1882

Derovatellus Sharp, 1882 (Figura 18)

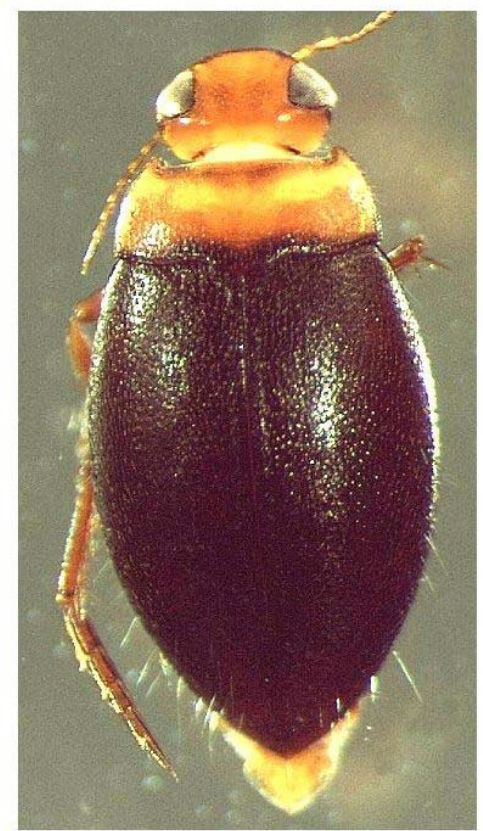

Figura 18 - Vista dorsal de Derovatellus (Derovatellus) lentus (Wehncke, 1876). Foto de Benetti, C. J., a partir de exemplares coletados no município de Gramado, RS.

$$
\text { D. (Derovatellus) } 1 \text { espécie }
$$

Macrovatellus Sharp, 1882 (Figura 19)

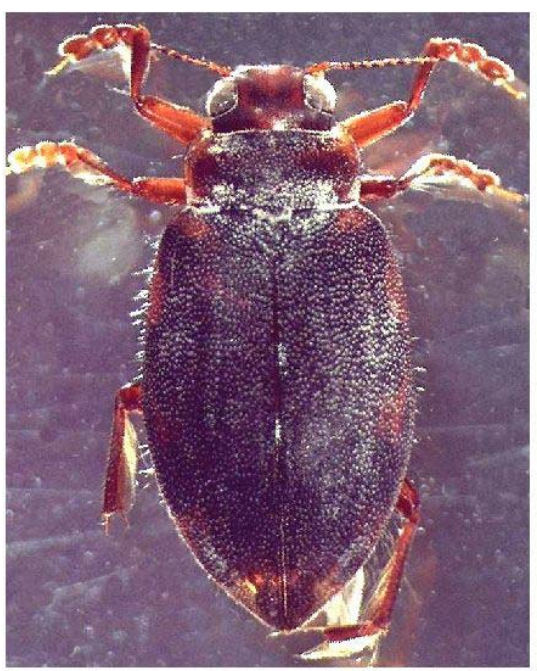

Figura 19 - Vista dorsal de Macrovatellus marginalis Sharp, 1882. Foto de Benetti, C. J., a partir de exemplares coletados no município de Gramado, RS.

\section{6 espécies}


Hydroporinae - Incertae sedis

Amarodytes Régimbart, 1900

6 espécies

(Figura 20)

Hydrodessus Balfour-Browne, 1953

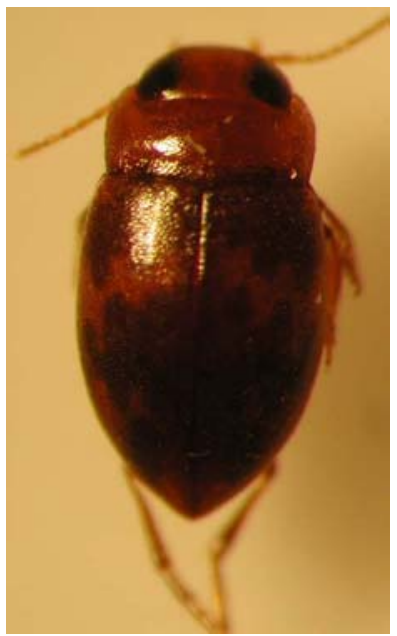

Figura 20 - Vista dorsal de Hydrodessus surinamensis Young, 1970. Foto de Benetti, C. J., a partir de exemplares coletados no município de Presidente Figueiredo, AM

Laccophilinae Gistel, 1856

$$
5 \text { espécies }
$$

(Figura 21)

Laccodytes Régimbart, 1895

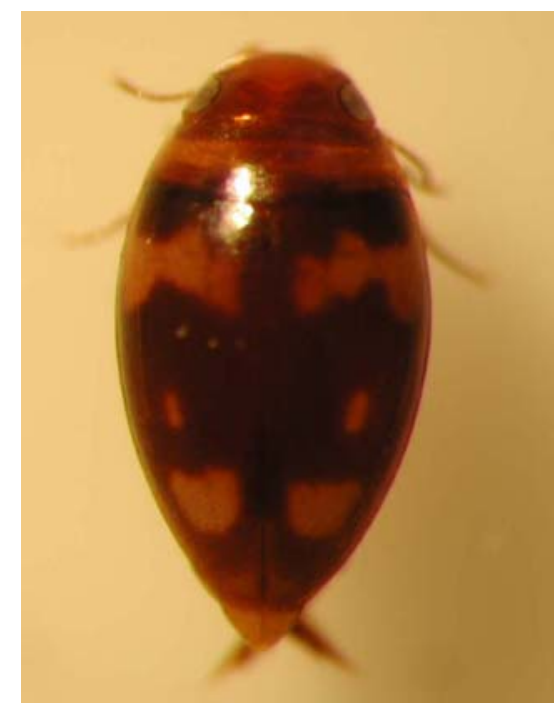

Figura 21 - Vista dorsal de Laccodytes sp. a partir de exemplares coletados no município de Manaus, AM
Laccophilus Leach, 1817

(Figura 22)

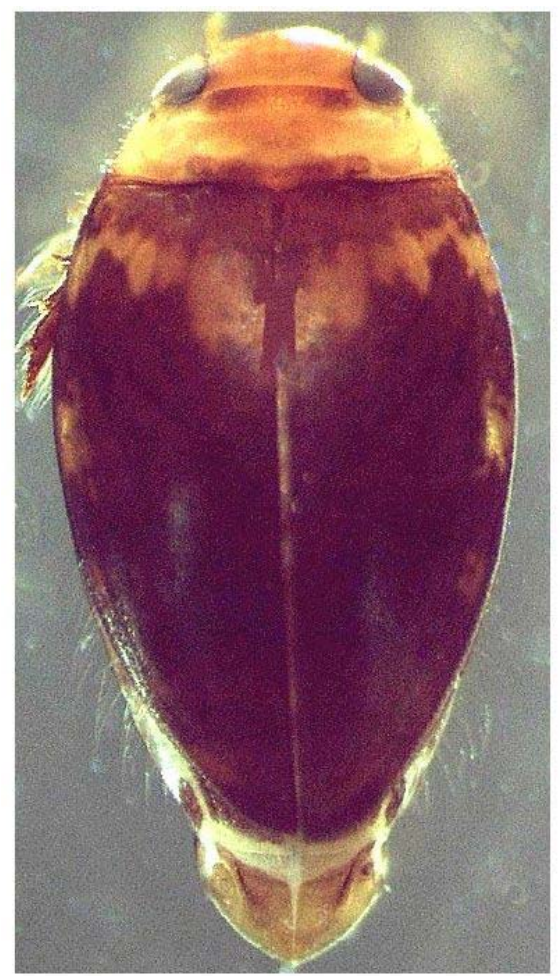

Figura 22 - Vista dorsal de Laccophilus ovatus Sharp, 1882. Foto de Benetti, C. J., a partir de exemplares coletados no município de Gramado, RS.

47 espécies

Hydrodytinae Miller, 2001

Hydrodytes Miller, 2001

2 espécies

Microhydrodytes Miller, 2002

1 espécie

Copelatinae Branden, 1884

Agaporomorphus Zimmermann, 1921

5 espécies

Aglymbus Sharp, 1882

5 espécies

2 espécies

http://www.biotaneotropica.org.br 
(Figura 23)

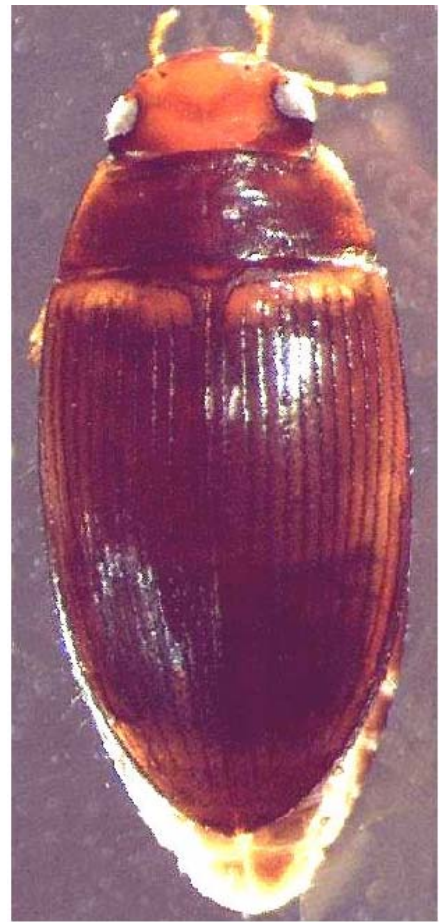

Figura 23 - Vista dorsal de Copelatus incognitus Sharp, 1882. Foto de Benetti, C. J., a partir de exemplares coletados no município de Gramado, $R S$.

$$
39 \text { espécies }
$$

Agabinae Thomson, 1867

Agabini Thomson, 1867

Platynectes Régimbart, 1879

(Figura 24)

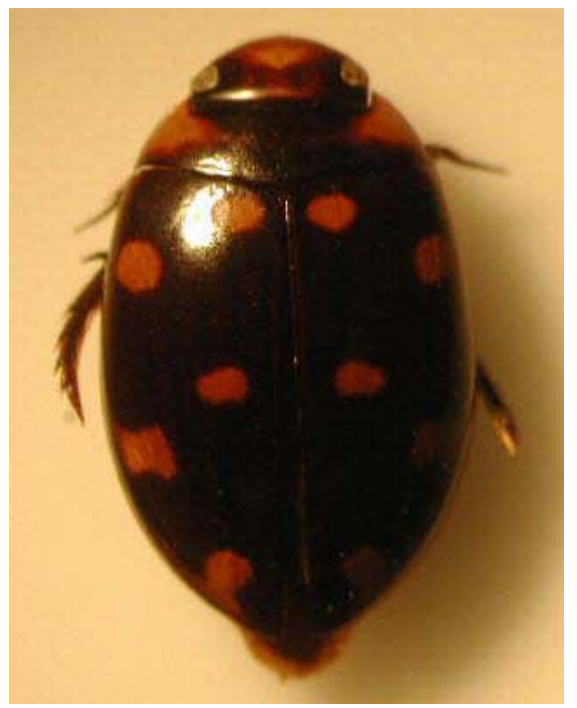

Figura 24 - Vista dorsal de Platynectes sp. a partir de exemplares coletados no município de Manaus, AM
P. (Platynectes) 5 espécies

Colymbetinae Erichson, 1837

Colymbetini Erichson, 1837 Rhantus Dejean, 1833 (Figura

25)

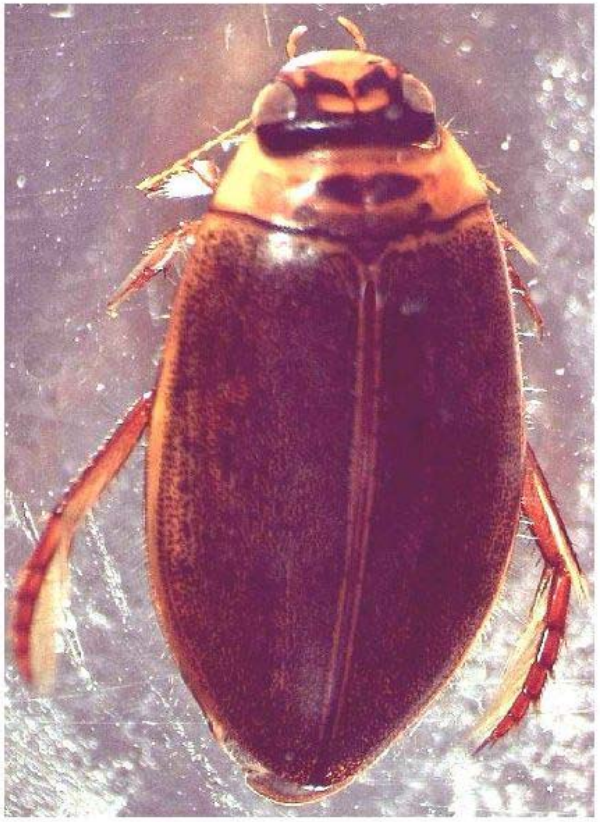

Figura 25 - Vista dorsal de Rhantus (Rhantus) signatus signatus (Fabricius, 1775). Foto de Benetti, C. J., a partir de exemplares coletados no município de Gramado, RS.

Lancetinae Branden, 1885

$R$. (Rhantus) 5 espécies

Lancetes Sharp, 1882

1 espécie

Dytiscinae Leach, 1815

Aciliini Thomson, 1867

Thermonectus Dejean, 1833

(Figura 26)

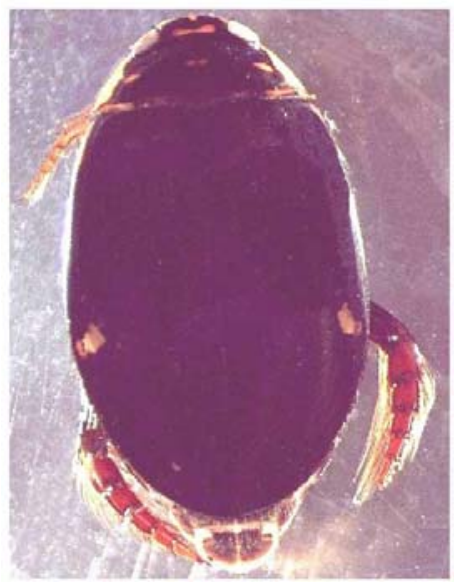

Figura 26 - Vista dorsal de Thermonectus marginegutathus (Aubé, 1838). Foto de Benetti, C. J., a partir de exemplares coletados no município de Gramado, RS. 
11 espécies

Aubehydrini Guignot, 1942

Notaticus Zimmermann, 1928

Cybistrini Sharp, 1882

1 espécie

Cybister Curtis, 1827

C. (Meganectes) 2 espécies

27)

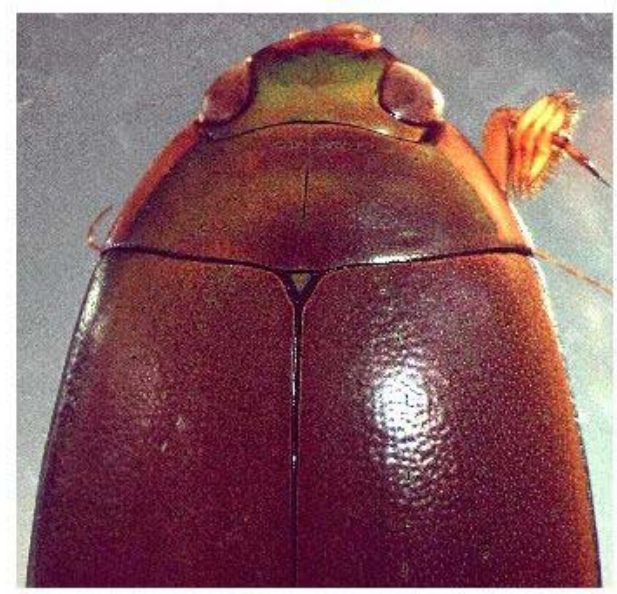

Figura 27 - Vista dorsal de Megadytes (Megadytes) fraternus Sharp, 1882. Foto de Benetti, C. J., a partir de exemplares coletados no município de Gramado, RS.

M. (Megadytes) 5 espécies M. (Bifurcitus) 3 espécies M. (Trifurcitus) 6 espécies M. (Paramegadytes) somente

M. glaucus (Brullé)

\section{Hydaticini Sharp, 1882}

Hydaticus Leach, 1817 (Figura

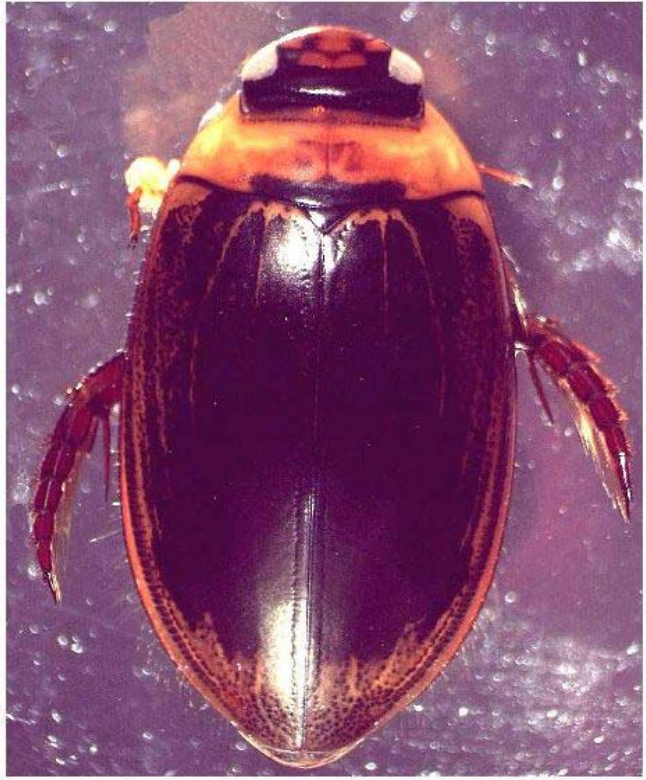

Figura 28 - Vista dorsal de Hydaticus (Guignotites) palliatus Aubé, 1838. Foto de Benetti, C. J., a partir de exemplares coletados no município de Gramado, RS.

H. (Guignotites) 6 espécies H. (Hydaticinus) 1 espécie

28) 
Chaves de identificação de gêneros de Hydradephaga (Coleoptera) citados para o Brasil

\section{Haliplidae}

Somente Haliplus

\section{Gyrinidae}

1. Élitros com pubescência lateral, sem fileiras de pontos (Fig.29). Escutelo não visível. Último segmento abdominal alongado, cônico e de aspecto triangular.....

Orectochilinae, Gyretes

1'Élitros glabros, normalmente com 11 fileiras de pontos. Escutelo visível. Último segmento abdominal obtuso, arredondado, não alongado .

2. Coxas posteriores mais largas na parte interna que na externa. A área côncava é mais estreita que a convexa. Asas metasternais em forma de triângulo. 17 a $22 \mathrm{~mm}$

Enhydrinae, Enhydrus

2' Coxas posteriores mais largas na parte externa que na interna (Fig.30). Asas metasternais estreitas e alongadas. 3,0 a 9,0 $\mathrm{mm}$

Gyrininae, Gyrinus

\section{Noteridae}

1. Tíbia anterior dilatada além da base dos tarsos com uma franja de espinhos marginais e com um esporão robusto e curvo (Fig.31). Processo prosternal truncado atrás ....................................................................................................................... 1'Tíbia anterior não dilatada além da base dos tarsos, sem espinhos e um esporão apical, ou com um espinho curto e débil (Fig.32). Processo prosternal arredondado atrás (Fig.33) .

[Notomicrini]...2

2. Tíbia anterior sem espinhos; fêmures posteriores com um pequeno tufo de cerdas longas no ângulo apical. Bordas da placa ventral não marginadas, tamanho inferior a $1,6 \mathrm{~mm}$....

..Notomicrus

2' Tíbia anterior com uma espinho pequeno e débil; fêmures posteriores sem um tufo de cerdas largas no ângulo apical, ou somente com umas poucas cerdas isoladas, tamanho superior a $1,75 \mathrm{~mm}$.

..Pronoterus

3. Tíbias anteriores triangulares (Fig.34), placa ventral alargada anteriormente.

Mesonoterus

3' Tíbias anteriores delgadas, paralelas (Fig.35), placa ventral estreitada anteriormente.

4. Forma do corpo muito alargada e convexa, quase esférica (Fig.36). Ápice dos élitros ligeiramente pontiagudo (Fig.37). Margem posterior da lâmina ventral quase reta, com duas indentações simétricas situadas a cada lado de sua linha média.

[Suphisini], Suphis

4' Corpo de forma alongada, oval, não esférico, acuminado atrás. Margem posterior da lâmina ventral com uma indentação mediana.

5. Margem interna do fêmur posterior com uma franja submarginal de cerdas curtas, porém sem penacho de cerdas no ângulo apical (Fig.38).

[Noterini], Siolius

5' Margem interna do fêmur posterior com uma franja submarginal de cerdas curtas e com um penacho de cerdas no ângulo apical.

[Hydrocanthini]...6

6. Processo prosternal quase tão largo como longo (Fig.39), no ápice com o triplo da largura da base; pronoto completamente marginado por um sulco.

Hydrocanthus

6’ Processo prosternal não tão largo como longo (Fig.40), no ápice com o dobro da largura da base...... 7

7. Bordas laterais do pronoto totalmente marginadas por um sulco que alcança a borda anterior.

Canthydrus

7' Bordas laterais do pronoto não inteiramente marginadas (Fig.41), com um sulco que não alcança a borda anterior

Suphisellus

http://www.biotaneotropica.org.br 


\section{Dytiscidae}

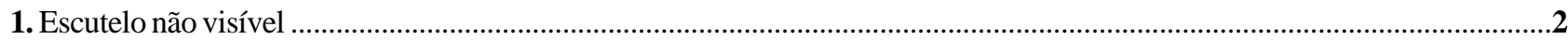

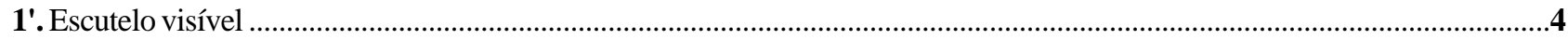

2. Protarsômeros masculinos 1-3 dilatados, com cerdas adesivas ventrais e com ápices circulares em forma de ventosa; comprimento do corpo geralmente maior que $6.5 \mathrm{~mm}$; élitros marrom escuros com uma banda transversal mais clara (Fig.42).

Dytiscinae; Aubehydrini, Notaticus

2' Protarsômeros masculinos 1-3 não dilatados, sem cerdas adesivas ventrais e com ápices ovais sem ventosas; comprimento do corpo menor que $6.5 \mathrm{~mm}$; desenho elitral diferente do anterior

3

3. Prosterno fortemente deprimido, com processo prosternal situado em plano distinto da porção anterior de prosterno; metatarsômeros 1-4 não lobulados na margem postero-apical

Hydroporinae (1)...6 3' Prosterno não fortemente deprimido, com processo prosternal no mesmo plano que a porção anterior do prosterno; metatarsômeros 1-4 fortemente lobulados na margem postero-apical .....

Laccophilinae...25

4. Élitros acuminados posteriormente; tergito VIII fortemente acuminado, na forma de espinho apical (Fig.43); protarsos pseudotetrâmeros em ambos sexos

Hydroporinae, Methlini, Celina

4' Élitros não acuminados posteriormente; tergito VIII não acuminado; protarsos pentâmeros em ambos sexos.. . .5

5. Olhos marginados ântero-lateralmente (Fig.44); machos com a superfície ventral dos pro- e mesotarsômeros expandida e com cerdas adesivas, porém não unidas formando uma ventosa oval ou arredondada (Fig.45) .....

5' Olhos não marginados ântero-lateralmente; machos com a superfície ventral dos pro- e mesotarsômeros expandida e com cerdas adesivas formando uma ventosa oval ou arredondada (Fig.46)

Dytiscinae....33

6. Metaepisterno separado das mesocoxas pelo mesoepímero; prosterno separado do metasterno (Fig.47)Vatellini....12 6' Metaepisterno em contato com as mesocoxas; prosterno em contato com o metasterno (Fig.48) .....

7. Unhas metatarsais desiguais em comprimento, a externa mais curta que a interna................................. Hyphydrini...13

7' Unhas metatarsais iguais ou quase iguais em comprimento .....

8. Cavidades metacoxais separadas; processo metacoxal dividido em três porções por duas excavações laterais, formando uma área mediana deprimida e um lóbulo lateral de cada lado que se estende à cavidade metacoxal, cobrindo a base do trocânter (Fig.49)

Hydrovatini...14

8' Cavidades metacoxais não separadas; processo metacoxal não dividido, com ou sem os lóbulos laterais cobrindo a base do trocânter (Fig.50)

9. Processo metacoxal situado em plano diferente ao do segmento abdominal adjacente, com os lóbulos laterais extendidos sobre as cavidades metacoxais e base do trocânter. Base do metafêmur em contato com o processo metacoxal (Fig.51)

Hydroporini, Laccornellus

9' Processo metacoxal situado no mesmo plano ao do segmento abdominal adjacente, sem lóbulos laterais extendidos sobre as cavidades metacoxais e base do trocânter

11. Pronoto com estria basal conectada a um sulco transversal irregular

12. Mesosterno grande, claramente visível a cada lado do processo prosternal; comprimento total do corpo: $5,0-8,0$ $\mathrm{mm}$.

Macrovatellus

12' Mesosterno pequeno, não visível; largura pronotal máxima na base, comprimento total do corpo: 3,8 - 4,1 mm

Derovatellus 
13. Processo prosternal alargado, ápice obtuso; mesocoxas separadas por aproximadamente a largura de uma coxa; labro não visível dorsalmente.

13' Proceso prosternal muito agudo, ápice bifurcado; mesocoxas separadas por quase a metade da largura de uma coxa; labro visível dorsalmente

Desmopachria

14. Incisões metacoxais mais curtas longitudinalmente que transversalmente (Fig.54); corpo não acuminado posteriormente; machos sem aparelho estridulador ventral; labro encoberto (Fig.55)

Queda

14' Incisões metacoxais mais longas longitudinalmente que transversalmente (Fig.49); corpo acuminado posteriormente; machos com ou sem aparelho estridulador ventral; labro visível, em parte, na região ventral .....

Hydrovatus

15. Cabeça com estria cervical transversal entre as margens posteriores dos olhos (Fig.56a) ......................................16

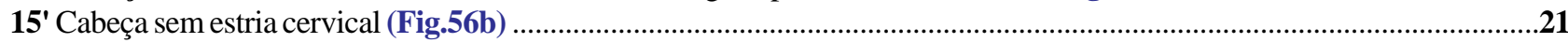

16. Epipleura escavada na base e limitada posteriormente por uma quilha oblíqua ....................................................17

16' Epipleura com a base escavada ou não, porém sem quilha oblíqua ..........................................................................18

17. Clípeo com dois tubérculos marginais evidentes

Brachyvatus

17' Clípeo com uma depressão marginal

Hemibidessus

18. Élitros com quilha sublateral; pontuação dorsal grossa, formando fileiras; pontuação ventral também grossa.....

Anodocheilus

18' Élitros sem quilha sublateral, pontuação dorsal e ventral fina a moderadamente grossa

..19

19. Protarsos com cinco tarsômeros (Fig.57a); mesotíbias fortemente curvadas

Bidessonotus

19' Protarsos pseudotetrâmeros, quarto tarsômero pequeno e coberto pelos lóbulos do terceiro segmento (Fig.57b); mesotíbias retas

20. Élitros com estria acessória de pontos entre a estria elitral principal e a sutura

Neobidessus

20' Élitros sem estria acessória (Fig.58)

Liodessus

21. Estrias pronotais reduzidas ou ausentes. Último esternito abdominal visível e marginado apicalmente.....Hypodessus 21' Estrías pronotais bem desenvolvidas (Fig.59). Último esternito abdominal visível mas não marginado apicalmente.

22. Élitros sem estria basal

22' Élitros com estria basal

23. Processo prosternal não marginado, ápice arredondado, truncado ou lanceolado (Fig.60); epipleuras escavadas na base, linhas metacoxais paralelas

Bidessodes

23' Processo prosternal marginado, ápice afilado; epipleuras não escavadas na base, linhas metacoxais divergentes anteriormente

Gramadessus

24. Edeago muito modificado, com vários processos apicais (Fig.61)

Microdessus

24' Edeago simples, sem processos apicais (Fig.62)

Uvarus

25. Espinho metatibial bifurcado no ápice

Laccophilus

25' Espinho metatibial simples Laccodytes

26. Ápice dos élitros sinuoso ou truncado (Fig.63) .

Lancetinae, Lancetes

26' Ápice dos élitros normal, não sinuoso nem truncado

27. Fêmur posterior com uma fileira linear de cerdas situadas no ângulo posterior externo (Fig.64). Agabinae, Platynectes

http://www.biotaneotropica.org.br 
27' Fêmur posterior sem fileira linear de cerdas com essa disposição.

28. Unhas metatarsais desiguais em comprimento, sendo a anterior mais curta

Colymbetinae, Rhantus

28' Unhas metatarsais iguais ou subiguais em comprimento; se desiguais, com a posterior levemente mais curta.

29. Cerdas natatórias dos metatarsos ausentes em ambos sexos, espermateca não reduzida, apódema anterior das gonocoxas presente.

Hydrodytinae ....30 29' Cerdas natatórias dos metatarsos presentes em ambos sexos ou somente em machos, espermateca reduzida, apódema anterior das gonocoxas ausente.

Copelatinae...31

30. Superfície dorsal brilhante, sem pontuação ou com pontos pequenos e indistintos. Tamanho superior a 2,5 $\mathrm{mm}$. Hydrodytes 30' Superfície dorsal sem brilho, opaca, com pontuação clara e distinta sobre os élitros. Tamanho inferior a 2,2 $\mathrm{mm}$.

Microhydrodytes

31 Sem linhas metacoxais

Aglymbus

31' Com linhas metacoxais (Fig.65)

32. Pronoto sem borda lateral, ou com uma borda pouco aparente; comprimento geralmente inferior a $3 \mathrm{~mm}$ Agaporomorphus 32' Pronoto com uma borda lateral estreita porém distinta; comprimento geralmente superior a $3 \mathrm{~mm}$ Copelatus

33. Espinhos metatibiais similares em forma. Protarsos dos machos transformados em uma paleta arredondada, ápice das cerdas adesivas ventrais arredondado, em forma de ventosa

33' Com um espinho metatibial grande e fortemente dilatado, e outros mais curtos e não dilatados. Protarsos dos machos transformados em uma paleta transversal de forma oval; ápice das cerdas adesivas ventrais não arredondado ou em forma de ventosa

Cybistrini...35

34. Espinho metatibial com ápice bífido.

Aciliini, Thermonectus

34' Espinho metatibial com ápice simples Hydaticini, Hydaticus

35. Com duas unhas metatarsais iguais ou quase iguais em ambos os sexos, ou fêmeas com a unha interna mais curta que a externa ..Megadytes 35' Com somente uma unha metatarsal em ambos os sexos, ou fêmeas com uma segunda unha muito reduzida. Cybister 


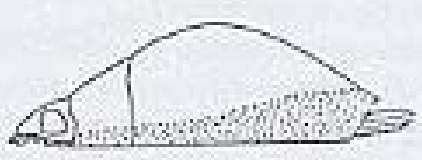

Figura 29 - Vista lateral de Gyretes sp. Modificada de Tremouilles et al 1995.

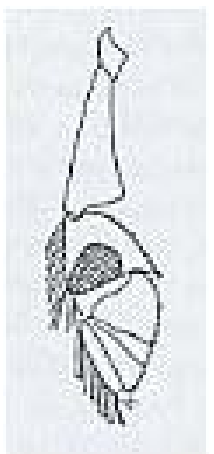

Figura 30 - Coxa posterior de Gyrinus sp. Modificada de Tremouilles et al 1995.

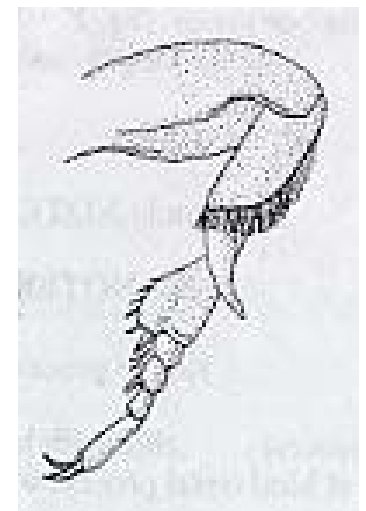

Figura 31 - Tíbia anterior de Hydrocanthus sp. Modificada de Pederzani, 1995.

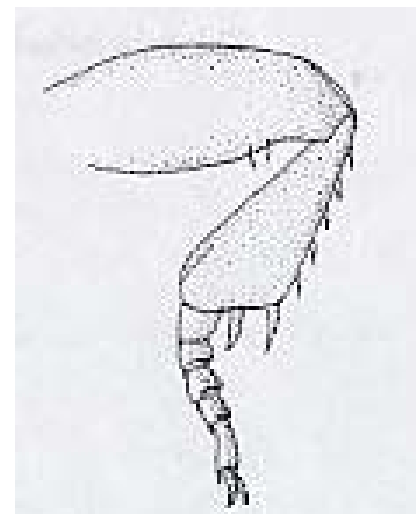

Figura 32 - Tíbia anterior de Notomicrus sp. Modificada de Pederzani, 1995.

http://www.biotaneotropica.org.br

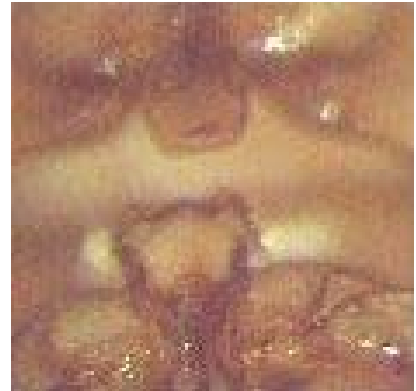

Figura 33 - Processo prosternal de Pronoterus punctipennis Sharp, 1882. Figura de Benetti, C.J., a partir de exemplares coletados em Gramado, RS.

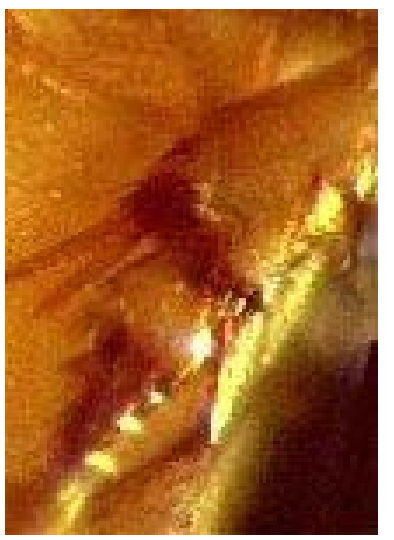

Figura 34 - Tíbias anteriores de Pronoterus punctipennis Sharp, 1882. Figura de Benetti, C.J., a partir de exemplares coletados em Gramado, $R S$

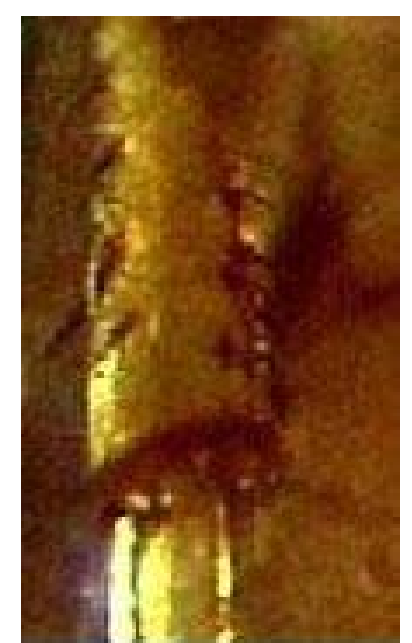

Figura 35 - Tíbias anteriores de Mesonoterus laevicollis Sharp, 1882. Figura de Benetti, C.J., a partir de exemplares coletados em Gramado, $R S$. 


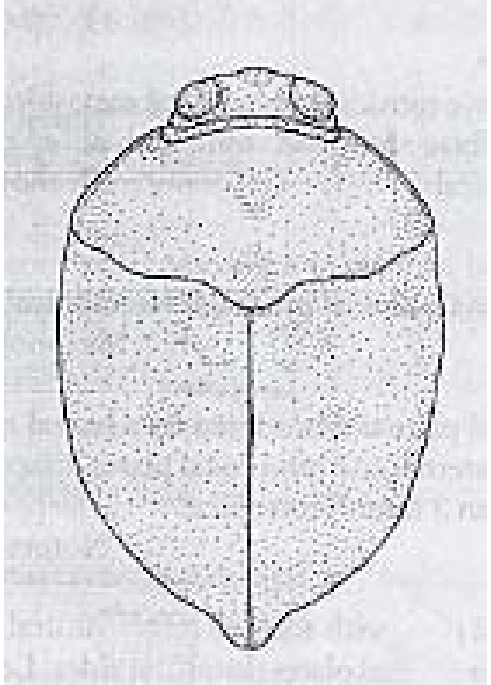

Figura 36 - Vista dorsal de Suphis sp. Modificada de Pederzani, 1995

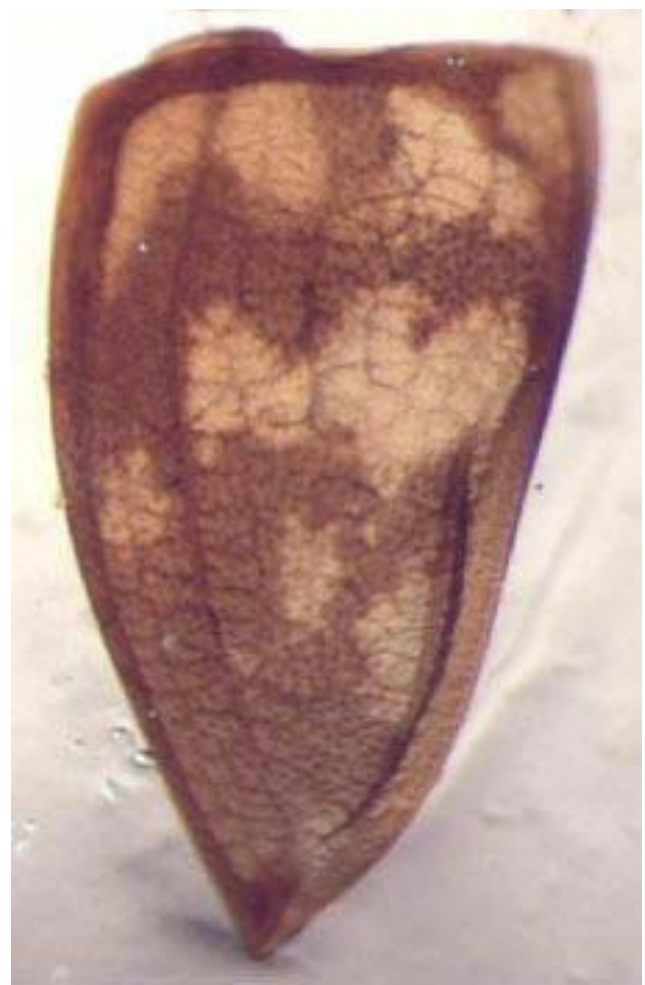

Figura 37 - Élitro direito de Suphis notaticollis Zimmermann 1921. Figura de Benetti, C.J., a partir de exemplares coletados em Gramado, $R S$.

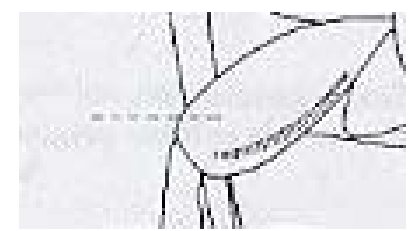

Figura 38 - Fêmur posterior de Noterus sp. Modificada de Pederzani, 1995

http://www.biotaneotropica.org.br

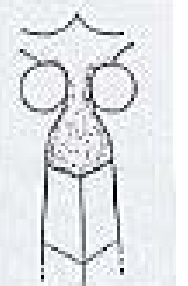

Figura 39 - Processo prosternal de Hydrocanthus sp. Modificada de Tremouilles et al 1995

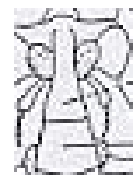

Figura 40 - Processo prosternal de Suphisellus sp. Modificada de Tremouilles et al 1995

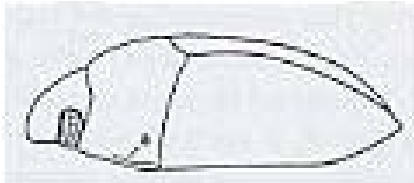

Figura 41 - Pronoto de Suphisellus sp. Modificada de Tremouilles et al 1995

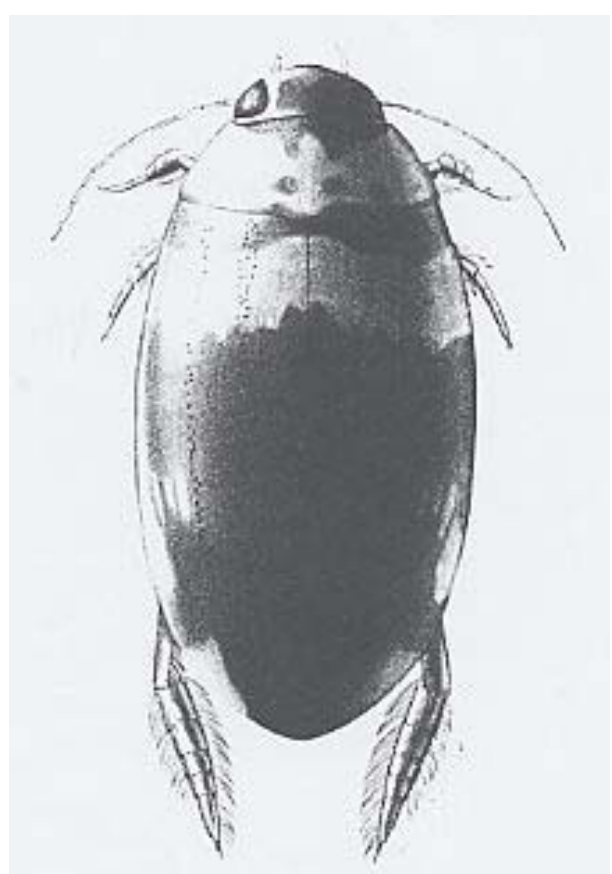

Figura 42 - Vista dorsal de Notaticus fasciatus Zimmermann, 1928. Modificada de Spangler, 1973. 


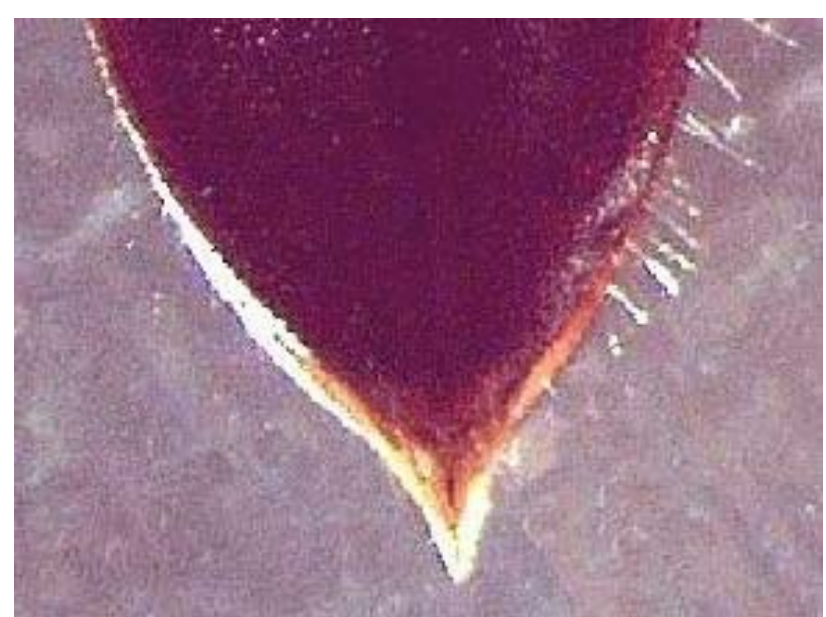

Figura 43 - Extremo apical dos élitros de Celina aculeata Aubé, 1838. Figura de Benetti, C.J., a partir de exemplares coletados em Gramado, $R S$

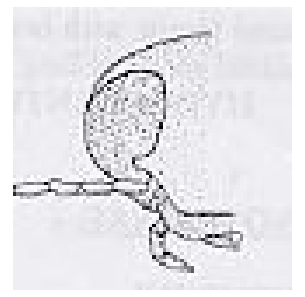

Figura 44 - Vista latero-marginal da cabeça de um exemplar hipotético de Colymbetinae. Modificada de Tremouilles et al 1995

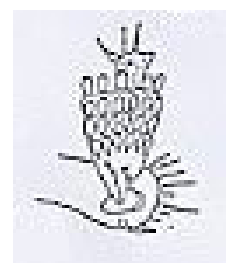

Figura 45 - Protarsos de Rhantus sp. Modificada de Tremouilles et al 1995

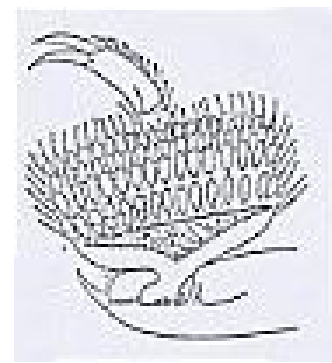

Figura 46 - Protarsos de Megadytes sp. Modificada de Tremouilles et al 1995

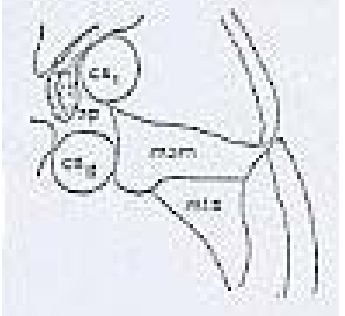

Figura 47 - Vista ventral anterior direita de Macrovatellus sp. Modificada de Tremouilles et al 1995

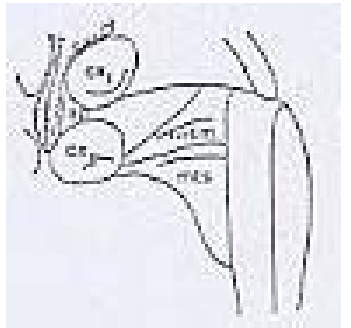

Figura 48 - Vista ventral anterior direita de Desmopachria sp. Modificada de Tremouilles et al 1995

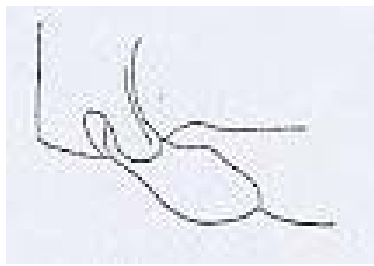

Figura 49 - Processo metacoxal de Hydrovatus villiersi Guignot, 1955. Modificada de Biström, 1996.

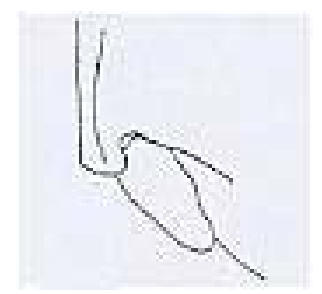

Figura 50 - Processo metacoxal de Derovatellus sp. Modificada de Biström, 1996.

http://www.biotaneotropica.org.br 


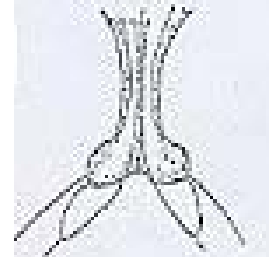

Figura 51 - Processo metacoxal de Laccornellus sp. Modificada de Tremouilles et al 1995

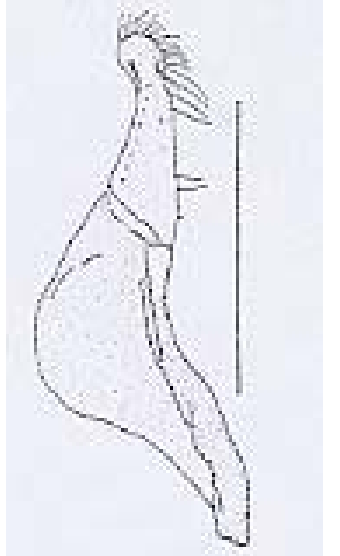

Figura 52 - Parâmero de Hypodessus cruciatus Régimbart, 1903. Modificada de Biström, 1988

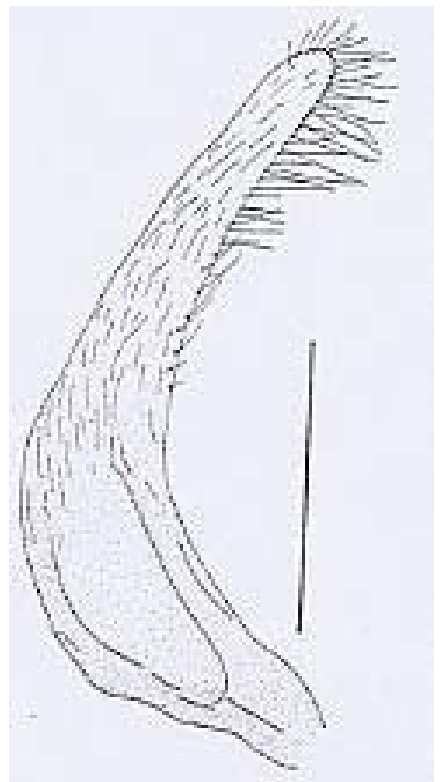

Figura 53 - Parâmero de Hydrodessus siolii J. Balfour-Browne, 1953. Modificada de Biström, 1988

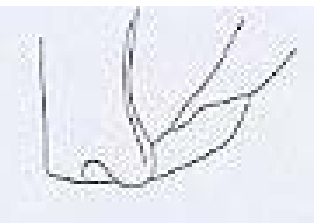

Figura 54 - Processo metacoxal de Queda youngi Biström, 1990 Modificada de Biström, 1996.

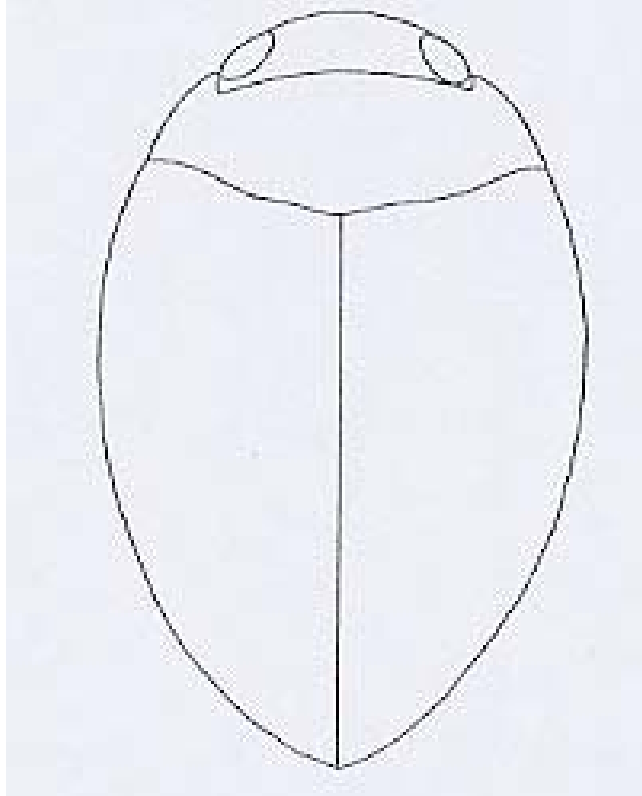

Figura 55 - Vista dorsal de Queda compressa Sharp, 1882. Modificada de Biström, 1990

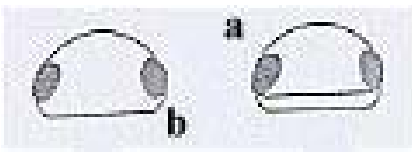

Figura 56 - Cabeça de um Bidessini hipotético (a - com estria cervical, $b$ - sem estria cervical). Modificada de Tremouilles et al 1995

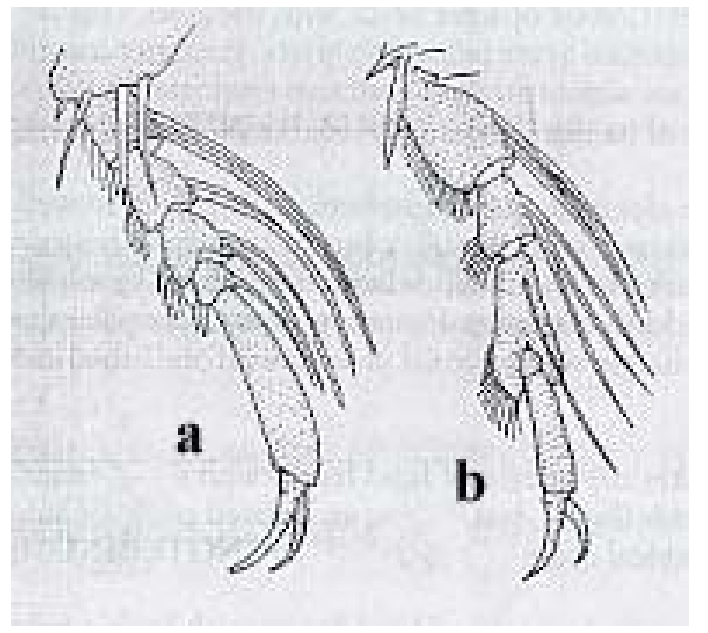

Figura 57a - Protarsos de Bidessonotus sp. Modificada de Pederzani, 1995

Figura 57b - Protarsos de Hydroporus sp. Modificada de Pederzani, 1995 


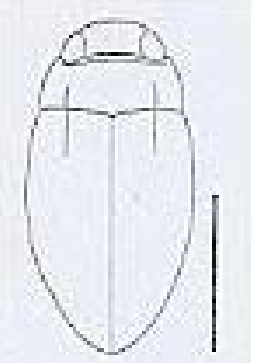

Figura 58 - Vista dorsal de Liodessus affinis (Say, 1823). Modificada de Biström, 1988

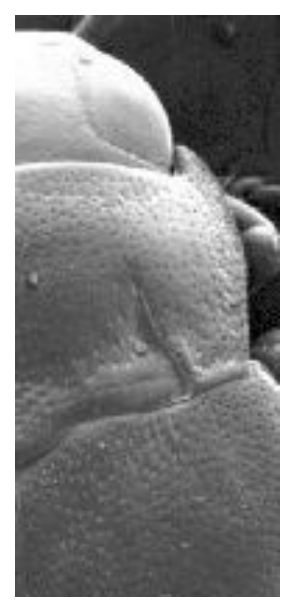

Figura 59 - Vista anterior direita de Gramadessus duponti (Aubé, 1838). Figura de Benetti, C.J., a partir de exemplares coletados em Gramado, RS.

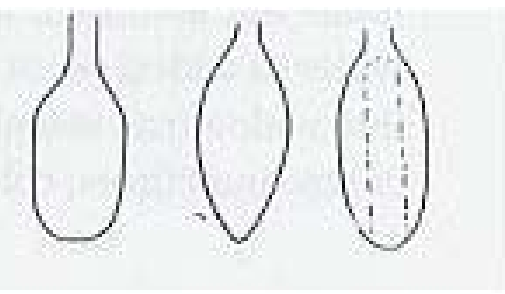

Figura 60 - Formas de processo prosternal encontradas em espécies de Bidessodes. Modificada de Young, 1986.

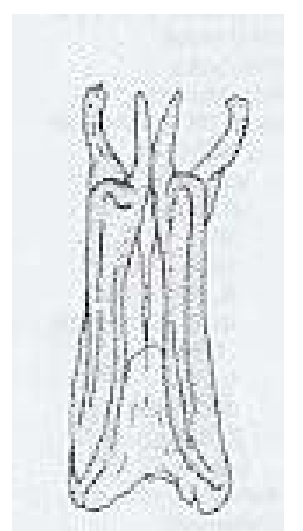

Figura 61 - Edeago de Microdessus atomarius (Sharp, 1882). Modificada de Biström, 1988

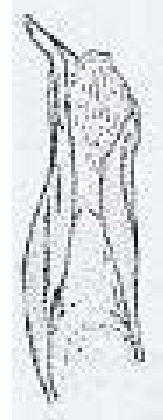

Figura 62 - Edeago de Uvarus lacustris (Say, 1823). Modificada de Biström, 1988



Figura 63 - Élitro direito de Lancetes marginatus (Steinheil, 1869). Figura de Benetti, C.J., a partir de exemplares coletados em Gramado, $R S$.

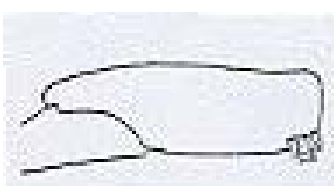

Figura 64 - Fêmur posterior de um exemplar hipotético de Agabinae. Modificada de Tremouilles et al 1995

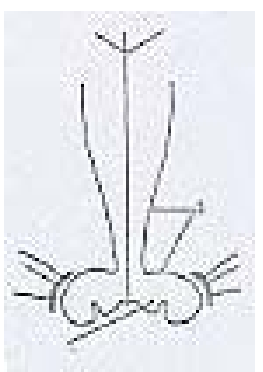

Figura 65 - Linhas metacoxais de Copelatus sp. Modificada de Tremouilles et al 1995

http://www.biotaneotropica.org.br 


\section{Referências}

BENETTI, C. J.; Fiorentin, G. L.; Regil Cueto, J. A. \& Pacho Miguel, R. R. 1998. Coleopterofauna aquática na Floresta Nacional de São Francisco de Paula, RS, Brasil. Acta biol.leopold. 20(1): 91-101.

BISTRÖM, O. 1988. Generic review of the Bidessini (Coleoptera,Dytiscidae). Acta zool.fenn. 184:1-41.

BISTRÖM, O. 1990. Revision of the genus Queda Sharp (Coleoptera: Dytiscidae). Quaest.ent. 26:211-220.

BISTRÖM, O. 1996. Taxonomic Revision of the Genus Hydrovatus Motschulsky (Coleoptera, Dytiscidae). Entomologica basil. 19:57-584.

BLACKWELDER, R. 1944. Checklist of the Coleopterous Insects of Mexico, Central America, the West Indies and South America. Bull.U.S.nat.Mus. 185(1):72-82

FERREIRA-Jr, N. 1993. Descrição da larva de Megadytes giganteus (Castelnau, 1834) com notas biológicas (Coleoptera:Dytiscidae). Revta bras.Ent. 37(1):57-60

FERREIRA-Jr, N. 1995. Description of the larvae of Megadytes fallax (Aubé) and M. marginithorax (Perty) (Coleoptera: Dytiscidae). Coleopts Bull. 49(4):313-318

FERREIRA-Jr, N. 2000. Morfologia externa da larva de Megadytes giganteus (Laporte, 1834) (Coleoptera, Dytiscidae) e evidências sobre a condição monofilética da tribo Cybistrini. Revta bras.Ent. 44(1/2):57-69

FERREIRA-Jr, N.; Mendonça, E.C.; Dorvillé, L.F.M. \& Ribeiro, J.R.I. 1998. Levantamento preliminar e distribuição de besouros aquáticos (Coleoptera) na Restinga de Maricá, Maricá, RJ. In. NESSIMIAN, J. \& CARVALHO, A. Ecologia de Insetos aquáticos. Oecol. bras. 5:129-140

LAWRENCE, J. F. \& NEWTON Jr, A. F. 1995. Families and Subfamilies of Coleoptera (with selected genera, notes, references and data on family-group names). In: PAKALUK, J. \& SLIPINSKI, S. A. Biology, Phylogeny and Classification of Coleoptera. Pap.Cel.80 ${ }^{\text {th }}$ Birthday of Roy A. Crowson: 779-1006.

MILLER, K. 2000. "Key to the subfamilies, tribes and genera of Neotropical Dytiscidae" http:// www.cals.cornell.edu/dept/entomolo...dytiscidae/ neotropical/neotropicalkey.htm (14/04/2000)

MILLER, K. B. 2001. On the phylogeny of the family Dytiscidae (Insecta: Coleoptera) with an emphasis on the morphology of the female reproductive tract. Insect Syst.Evol. 32:45-92

MILLER, K. B. 2002. Revision of the subfamily Hydrodytinae Miller (Coleoptera: Dytiscidae) with Description of a New Genus. Insect Syst.Evol. 33:1-8
OCHS, G. 1935. Die brasilianische Artengruppe der Gattung Gyrinus, Untergattung Neogyrinus Hatch (Coleoptera, Gyrinidae). Rev.Ent., Rio de J. 5:124-132.

OCHS, G. 1948. Checklist of Neotropical Gyrinoidea. Rev.Ent., Rio de J. 19:565-567.

PEDERZANI, F. 1995. Keys to the identification of the genera and subgenera of adults Dytiscidae (sensu lato) of the world (Coleoptera Dytiscidae). Atti Acc.Rov.Agiati, a. 244(1994), ser. VII(4B):5-83.

RÉGIMBART, M. 1902. Coleoptera, Fam. Gyrinidae. In: WYTSMAN, P. Genera Insectorum 1:1-12.

RÉGIMBART, M. 1903. Liste des Dytiscidae et Gyrinidae recuillis par le Dr. Philippe Silvestri dans l'Amérique méridionale de 1898 a 1900. Boll.Soc.ent.ital. 35: 46-74.

SPANGLER, P. J. 1973. The nomenclature, bionomics, and distribution of Notaticus fasciatus (Coleoptera: Dytiscidae: Aubehydrinae). Proc.biol.Soc.Wash. 86(42):495-500.

TRÉMOUILLES, E. R. 2000. Observaciones sobre el género Leuronectes Sharp, aspectos de su morfología y distribución geográfica (Coleoptera, Dytiscidae, Agabini). Revta Mus.argent.Cienc.nat. 2(2):195-202.

TRÉMOUILLES, E. R., OLIVA, A. \& BACHMANN, A. 1995. Insecta. Coleoptera. In: LOPRETTO, E. C. \& TELL, G., Ecossistemas de Aguas Continentales: 1133-1195. Ediciones Sur, La Plata.

YOUNG, F. N. 1986. Review of the Predaceous Water Beetles of the Genus Bidessodes Régimbart (Coleoptera, Dytiscidae). Entomologica basil. 11:203-220.

Título: Gêneros de Hydradephaga (Coleoptera: Dytiscidae, Gyrinidae, Haliplidae, Noteridae) citados para o Brasil, com chaves para identificação.

Autores:Cesar João Benetti1, Juan Antonio Régil Cueto Gelson Luiz Fiorentin

Biota Neotropica volume3 (número 1): 2003 http://www.biotaneotropica.org.br/v3n 1/pt/ abstract?identification-key+BN00803012003

Recebido em: 14/02/2003

Publicado em: 26/03/2003

ISSN 1676-0603 